\title{
Pneumonia During COVID-19 Pandemic in Hospitalized Children. Characterization of SARS-COV2 Pneumonia . Multi-Center Cohort Study
}

\author{
Hassan Al-Asy ${ }^{1}$, Osama Toema ${ }^{2}$, Rehab Elmezawy², Mohammed Hamza², Omar Hasanin ${ }^{2}$, \\ Maali Mabrouk ${ }^{2}$, and Manal Aldiba ${ }^{3}$ \\ ${ }^{1}$ Tanta Faculty of Medicine - Tanta University \\ ${ }^{2}$ Tanta University Faculty of Medicine \\ ${ }^{3}$ Almenshawy General Hospital
}

February 22, 2022

\begin{abstract}
Abstract : Although COVID-19 is milder in young than adults. However, it can cause pneumonia in children eventually requiring hospitalization. Clinical similarity between COVID-19, other viral, and bacterial pneumonia at initial presentation of the disease caused a great challenge. We aimed to differentiate COVID-19 pneumonia from other viral and bacterial pneumonia in children, and to characterize it . Materials and Methods: This study included 300 children, who were hospitalized with clinically and radiologically confirmed pneumonia during COVID-19 pandemic. Clinical symptoms were collected and analyzed - Cultures, real time polymerase chain transcriptase test for some respiratory viruses and SARS-COV2, C-reactive protein, serum procalcitonin ,serum ferritin, complete blood counts, and ferritin/procalcitonin ratio were done for all patients Results: This study showed that COVID-19 pneumonia was only $15 \%$ of all admitted pneumonia cases. It had low proportion of high fever, mild course, significant lymphopenia, significant thrombocytopenia, low procalcitonin, low C-reactive protein , higher ferritin / procalcitonin ratio, and higher neutrophil/ lymphocyte ratio, significant high percentage of ground glass , and less percentage of consolidation in CT images . Conclusion: During ( COVID-19) outbreak, pneumonia due to COVID-19 was less common, and less severe than that caused by other viruses or bacteria in children. Naso- pharyngeal swabs for multi-respiratory pathogen, including SARS-COV-2, are required to not to attribute most pneumonia cases to be due to COVID-19. However , further large-sample studies are needed to have full blown picture about COVID-19 pneumonia in children.
\end{abstract}

\section{Hosted file}

Copy of TEXT.docx available at https://authorea.com/users/461826/articles/557430-pneumoniaduring-covid-19-pandemic-in-hospitalized-children-characterization-of-sars-cov2pneumonia-multi-center-cohort-study

\section{Hosted file}

tables for magazine.docx available at https://authorea.com/users/461826/articles/557430pneumonia-during-covid-19-pandemic-in-hospitalized-children-characterization-of-sarscov2-pneumonia-multi-center-cohort-study 